\title{
PEMBELAJARAN GEOMETRI BIDANG DAN RUANG BERBASIS ETNIS TIMOR
}

\author{
Michael Fernandez ${ }^{1)}$, Kristoforus Djawa Djong ${ }^{2)}$, Wilfridus B. N Dosinaeng ${ }^{3)}$, Irmina V \\ Uskono $^{4)}$, Aloysius Joakim Fernandez ${ }^{5)}$, Meryani Lakapu ${ }^{6}$ \\ Pendidikan Matematika, FKIP, Universitas Katolik Widya Mandira, Indonesia ${ }^{1), 2), 3,4), 55,6)}$ \\ Pos-el : fernandezmichael1518@gmail.com ${ }^{1)}$;louisnandez@unwira.ac.id ${ }^{5)}$
}

\begin{tabular}{l|l|l} 
Dikirim: 28, 07, 2020 & Direvisi: 11, 08, 2020 & Diterbitkan: 31, 08, 2020
\end{tabular}

\begin{abstract}
Abstrak
Etnomatematika mengacu pada bentuk-bentuk matematika yang bervariasi sebagai konsekuensi yang tertanam dalam kegiatan budaya. Etnomatematikajuga mengacu pada konsep-konsep matematika tertanam dalam praktek-praktek budaya. Etnomatematika mengacu pada bentuk-bentuk matematika yang bervariasi sebagai konsekuensi yang tertanam dalam kegiatan budaya. Geometri sebagai salah satu mata pelajaran yang diajarkan di tingkat Sekolah Dasar dan Sekolah menengah. Pembelajaran geometri berbasis etnis budaya Timor. Siswa dapat mengamati dan menghitung banyaknya bentuk geometri dalam LOPO. Implementasi bentuk-bentuk Geometri (bidang datar dan ruang) dalam pelaksanaan pembelajaran Geometri berbasis etnis budaya Timor menjadi suatu metode yang tepat. Siswa dapat mengamati dan mengkaji Geometri dalam rumah adat LOPO. Kelompok sasaran dalam kegiatan Pengabdian ini yaitu sekolah-sekolah yang siswanya kebanyakan berasal dari Suku Dawan (TTU dan TTS serta Kabupaten Kupang). Kelompok sasarannya adalah siswa-siswi SMPN 10.Agar dapat mengimplementasi bentuk-bentuk geometri dalam pelaksanaan pembelajaran Geometri berbasis etnis budaya Timor, maka dapat dilakukan dengan cara membuat miniatur LOPO yang dibawa ke depan kelas saat kegiatan pembelajaran Geometri. Namun demikian disarankan agar sekolah itu dapat membuat LOPO yang sebenarnya, sehingga LOPO itu menjadi sumber belajar bagi siswa yang belajar tentang geometri bidang datar dan geometri ruang.
\end{abstract}

Kata Kunci: Etnomatematika, Geometri, LOPO

\begin{abstract}
Ethnomatematics refers to various forms of mathematics as consequences that are embedded in cultural activities. Ethnomatematics also refers to mathematical concepts embedded in cultural practices. Ethnomatematics refers to various forms of mathematics as consequences that are embedded in cultural activities. Geometry as one of the subjects taught at the Elementary School and Middle School level. Learning geometry based on ethnic Timorese culture. Students can observe and count the number of geometric shapes in LOPO. The implementation of Geometry forms (plane and space) in the implementation of ethnic based learning of Timor culture becomes an appropriate method. Students can observe and study Geometry in the traditional house, LOPO. The target groups in the Community Service activities are the schools where the students are mostly from the Dawan tribe (TTU and TTS and Kupang Regency). The target group is students of SMPN 10. In order to be able to implement Geometric forms in the implementation of Geometry learning based on ethnic Timorese culture, it can be done by making a miniature LOPO which is brought to the front of the class during Geometry learning activities. However, it is suggested that the school can make a real LOPO, so that LOPO becomes a source of learning for students who learn about geometry of planeand geometry of space.
\end{abstract}

Keywords: Ethnomatematics, Geometry, LOPO 


\section{PENDAHULUAN}

Pendidikan bertujuan untuk memanusiakan manusia. Memanusiakan manusia diartikan membuat manusia agar dapat menjadi manusia yang sesuai dengan tuntutan manusia itu sendiri. Manusia secara ideal yang mampu bertaqwa kepada Tuhan yang maha Esa, serta memiliki ilmu dan pengetahuan yang dapat bermanfaat bagi kehidupan manusia lainnya. Manusia yang memiliki kemampuan berpikir yang berbeda dengan makluk ciptaan Tuhan yang lainnya.

Idealnya pendidikan tidak hanya berorientasi pada masa lalu dan pada saat sekarang, tetapi sudah merupakan suatu proses untuk mengantisipasi dan merencanakan masa depan suatu bangsa.Pendidikan melihat lebih jauh ke depan dan memikirkan apa yang akan dihadapi manusia di masa depan sehingga dapat menghasilkan manusia yang berkualitas, karena kemajuan suatu bangsa tidak lepas dari pendidikan yang telah diberikan pada masyarakatnya.

Dengan demikian peningkatan mutu pendidikan merupakan syarat utama dan harus dilakukan secara menyeluruh yang mencakup pengembangan aspek-aspek manusia Indonesia seutuhnya, yakni pengetahuan, kreativitas, dan sikap yang mencakup akhlak, budi pekerti, dan moral serta keterampilan dalam berpikir atau dalam mengerjakan suatu pekerjaan. Pengembangan aspek-aspek tersebut bermuara pada peningkatan dan pengembangan kecakapan hidup yang diwujudkan melalui pencapaian kompetensi mahasiswa untuk mampu menyesuaikan diri dan berhasil di masa mendatang.

Matematika merupakan salah satu pelajaran yang dapat digunakan untuk mengembangkan pengetahuan, kreativitas, dan sikap yang mencakup akhlak, budi pekerti, dan moral serta keterampilan dalam berpikir atau dalam mengerjakan suatu pekerjaan. Matematika merupakan mata pelajaran yang bertujuan secara formal untuk menata nalar seseorang dan secara material untuk mengembangkan pengetahuan serta aplikasinya dalam kehidupan setiap hari. Hal ini berarti bahwa matematika berkaitan dengan kehidupan sosial masyarakat setiap hari.

Perkembangan matematika tidak dapat terlepas dari budaya setempat. Budaya diartikan sebagai kumpulan norma atau aturan umum yang berlaku di masyarakat, kepercayaan, dan nilai yang diakui pada kelompok masyarakat yang berada pada suku atau kelompok bangsa yang sama Hammond (2000). Dengan demikian norma atau aturan itu dituangkan dalam bentuk gambar atau lukisan pada bangunan rumah atau pada badan manusia. Gambar-gambar itu dibuat namun tidak disadari ada bentuk-bentuk matematika khususnya Geometri, baik itu Geometri bidang datar atau geometri ruang. Hal ini mengandung makna bahwa sebenarnya manusia yang berbudaya, tanpa ada pengetahuan awal matematika, sudah dapat menggunakan matematika dalam hidupnya. Sepertinya matematika ada bersamaan dengan budaya setempat. Ketika budaya berkembang, maka matematika juga berkembang, walau kadang perkembangan matematika dalam budaya, sangat tidak disadari. Dari pengertian ini, muncul konsep tentang etnomatematika. Etnomatematika merupakan matematika yang tumbuh dan berkembang dalam kebudayaan tertentu.

Etnomatematika merupakan sebuah studi tentang perbedaan cara masyarakat memecahkan masalah matematika dan algoritma praktis berdasarkan perspektif matematika mereka sendiri. Etno-matematika mengacu pada bentuk-bentuk matematika yang bervariasi 
sebagai konsekuensi yang tertanam dalam kegiatan budaya. Dalam perspektif ini, (Orey, 2018) menegaskan, "mungkin Ethnomathematics ditandai sebagai alat untuk bertindak di dunia" dan dengan demikian, memberikan wawasan peran sosial matematika dalam bidang akademik. Etnomatematika mengacu pada konsep-konsep matematika tertanam dalam praktek-praktek budaya dan mengakui bahwa semua budaya dan semua orang mengembangkan metode unik untuk memahami dan mengubah realitas komunitas budaya (Orey, 2018). Etnomatematika merupakan sebuah studi tentang perbedaan cara masyarakat memecahkan masalah matematika dan algoritma praktis berdasarkan perspektif matematika masyarakat sendiri. Etnomatematika mengacu pada bentuk-bentuk matematika yang bervariasi sebagai konsekuensi yang tertanam dalam kegiatan budaya.

Etnomatematika dapat dideskripsikan sebagai suatu cara dimana masyarakat dari budaya tertentu menggunakan ide dan konsep secara matematika melalui pertimbangan secara kuantitatif, relasional dan aspek-aspek keruangan hidup masyarakat. Cara pandang matematika memvalidasi dan menentukan seluruh pengalaman masyarakat akan matematika menunjukan bahwa berpikir secara matematika sesuai dengan kehidupan masyarakat. Pembuktian lebih lanjut dari penilaian tersebut diberikan oleh (Orey, 2018) yang menyatakan bahwa "paradigma bahwa budaya yang berbeda menggunakan atau bekerja dengan interaksi yang unik antara bahasa dengan budaya lingkungan mereka". Dengan pandangan ini Ambrosio (2018) menganggap bahwa pada pandangan etno-mathematika, berpikir matematika dikembangkan pada budaya yang berbeda tergantung pada permasalahan yang ditentukan melalui konteks budaya.

Etnomatematika merupakan bidang penyelidikan yang mempelajari ide-ide matematika dalam konteks kebudayaan-sejarah komunitas budaya. Gambar di samping lukisan kayu suku Asmat (koleksi pribadi). Di sisi lain matematika khususnya Geometri, dalam jangka waktu yang lama dianggap sebagai cabang ilmu Matematika. Matematika diidentifikasi dalam kegiatan budaya dalam masyarakat tradisional dan non-tradisional (Orey \& Rosa,2007). Ini berarti bahwa ethnomathematics mengacu pada konsep-konsep matematika tertanam dalam praktek budaya dan mengakui bahwa semua budaya dan semua orang mengembangkan metode unik untuk memahami dan untuk mengubah realitas masyarakat sendiri (Orey, 2018). Hal ini juga mengakui bahwa metode akumulasi budaya ini terlibat dalam sebuah proses yang konstan, dinamik dan alami evolusi dan pertumbuhan.

Matematika sebagai suatu pelajaran mempunyai dua tujuan utama yaitu tujuan secara formal, menata nalar peserta didik dan tujuan secara material, mengembangkan matematika itu sendiri dan menerapkan matematika pada ilmu lainnya.

Domain konten sejalan dengan materi (konten) pada standar isi mata pelajaran matematika SMP yaitu: bilangan (number), aljabar (Algebra), geometri (Geometry), data dan peluang (Data and chance). Sedangkan domain koqnitif terdiri dari pengetahuan (knowing), penerapan (applying) dan penalaran (reasoning). Soal-soal yang dikembangkan oleh TIMSS menuntut peserta didik untuk berpikir dari tingkat rendah sampai ke tingkat tinggi. Soal-soal yang memuat tuntutan berpikir tingkat tinggi berkaitan dengan ranah koqnitif penalaran yang antara lain mencakup kemampuan menemukan konjektur, analisis, generalisasi, koneksi, sintesis, pemecahan masalah yang tidak rutin dan jastifikasi atau pembuktian. 
Dalam Kurikulum 2013, pembelajaran matematika dengan pendekatan saintifik, tidak sekedar memindahkan pengetahuan dari guru ke siswa, namun pembelajaran matematika yang menyebabkan siswa dapat berpikir kritis, kreatif dan memecahkan masalah matematika dengan langkah kerja saintifik. Berpikir kritis dalam matematika diartikan sebagai kemampuan mengikuti suatu algoritma dalam memecahkan masalah matematika dengan menggunakan konteks budaya lokal. Salah satu rumah adat Etnis Timor, Ume Kbubu yang digunakan sebagai konteks pembelajaran matematika pada materi bangun ruang membuat guru kreatif dan memudahkan siswa dalam memahami materi geometri (Amsikan \& Deda, 2018). Salah satu pokok bahasan yang diajar di Sekolah Menengah Pertama yaitu geometri, khususnya Geometri Bidang Datar dan Ruang. Berdasarkan latar belakang di atas, maka kami membuat kegiatan pengabdian pada masyarakat dengan judul: Pembelajaran Geometri Bidang Dan Ruang Berbasis Etnis Timor

\section{METODE}

Kelompok sasaran dalam kegiatan Pengabdian ini yaitu sekolah-sekolah yang siswanya kebanyakan berasal dari suku dawan (TTU dan TTS serta Kabupaten Kupang). Pengambilan sekolah ini berkaitan dengan implementasi pembelajaran geometri berdasarkan etnis Timor.Pengabdian ini dilakukan di SMPN 10 Kota Kupang.

Subyek dari pengabdian ini yaitu etnis budaya Timor yang tertuang dalam bentuk bangunan rumah yang ada pada LOPO yang ada di SMPN 10 serta pelaksanaan pembelajaran geometri bidang datar dan ruang berdasarkan etnis dan budaya Timor. Selain itu subyek pengabdian yaitu guru matematika dan siswa SMPN 10 yang ikut serta dalam suatu proses pembelajaran geometri. Guru yang diambil sebagai subyek yaitu guru matematika yang mengajar geometri sisi datar dan ruang serta geometri sisi lengkung. Selanjutnya siswa yang diambil sebagai subyek pengabdian yaitu siswa yang belajar geometri sisi datar dan Ruang serta geometri sisi lengkung.

\section{HASIL DAN PEMBAHASAN}

\section{A. Rancangan Kegiatan}

Kegiatan ini dilakukan dalam tiga tahap yaitu:

\section{Tahap I:}

Pada tahap ini, dosen dan guru matematika merencanakan kegiatan pembelajaran geometri bidang datar dan ruang berdasarkan etnis Timor. Etnis Timor dalam hal ini berkaitan bentuk geometri yang ada dalam bangunan LOPO. Bangun geometri yang ada yaitu bangun datar dan bangun ruang. Dalam hal ini guru dan dosen merancang RPP untuk melaksanakan pembelajaran berdasarkan etnis Timor. Guru dan dosen serta beberapa mahasiswa membuat suatu LOPO sederhana yang akan digunakan dalam pembelajaran Matematika, khususnya geometri bidang datar dan geometri ruang.

Dalam konteks ini, dosen dan guru bidang studi matematika bersama beberapa mahasiswa membuat miniatur LOPO. Miniatur LOPO ini secara struktur nampak bagian dalamnya. Diharapkan siswa yang mengamati bentuk geometri yang ada pada bagian dalam LOPO itu. 


\section{Tahap II}

Pada tahap ini, dosen dan guru matematika melaksanakan kegiatan pembelajaran geometri bidang datar dan ruang berdasarkan etnis Timor. Dalam hal ini guru dan dosen melaksanakan pembelajaran dengan menggunakan RPP yang telah disusun berdasarkan etnis Timor. Guru dan dosen menggunakan miniatur LOPO sederhana yang digunakan dalam pembelajaran Matematika, khususnya geometri bidang datar dan geometri ruang. LOPO yang dibuat dapat dilihat pada gambar berikut:

\section{Tahap III}

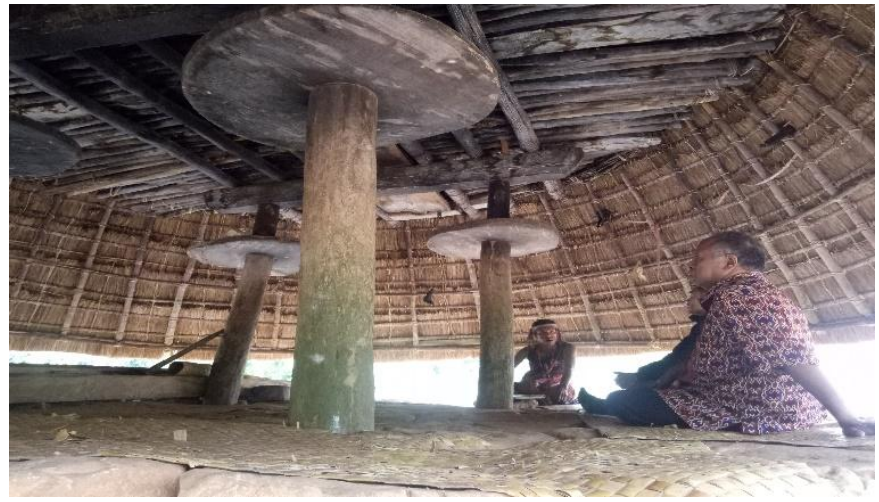

Gambar 1: Lopo Asli Etnis Timor

(Nampak bagian Dalam)

Pada tahap ini, dosen dan guru matematika melakukan diskusi bersama siswa tentang pelaksanaan pembelajaran geometri bidang datar dan ruang berdasarkan etnis Timor. Diskusi berkaitan dengan bentuk geometri dalam LOPO. Selanjutnya diskusi juga berkaitan dengan pembelajaran geometri bidang datar dan ruang berdasarkan etnis Timor.

\section{B. Pelaksanaan Kegiatan}

\section{B.1. Membuat Miniatur LOPO}

Pembuatan miniatur LOPO dilaksanakan bersama antara dosen dan mahasiswa yang terlibat dalam kegiatan pengabdian ini.

Pembuatan diawali dengan membuat batang-batang kayu yang dibutuhkan dan dengan penggunakan alat pertukangan yang ada, dihasilkan bentuk tiang dan usuk-usuk.

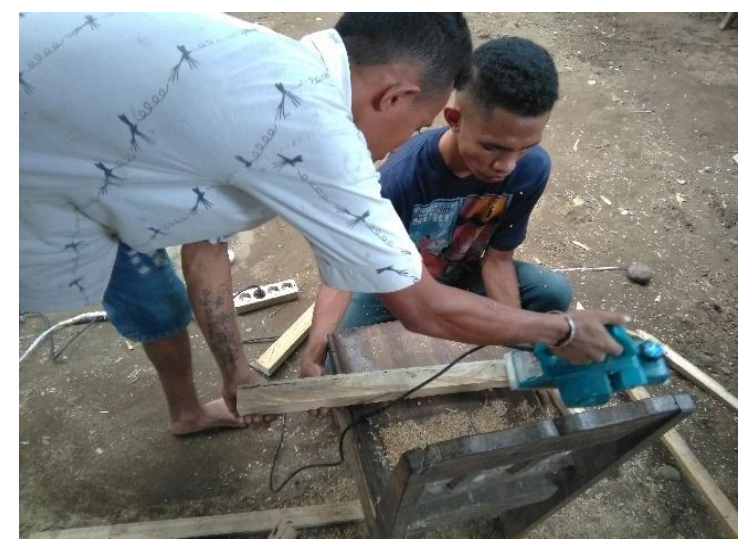

Gambar 2: Membuat Kerangka LOPO 
Selanjutnya dilakukan konstruksi bagian-bagian dari LOPO yaitu bagian tiang dan bagian dalamnya.

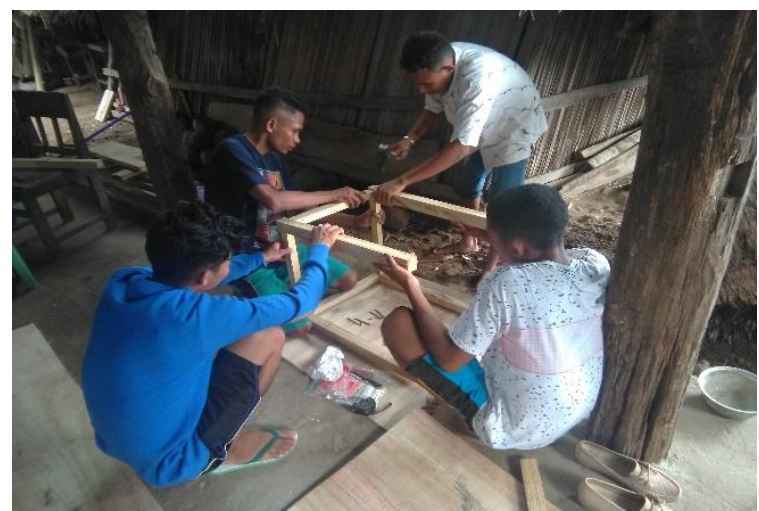

Gambar 3: Mengkonstruksi Bangunan LOPO

\section{B.2. Pelaksanaan Pembelajaran}

Kegiatan ini dilaksanakan di salah satu kelas di SMPN 10 Kota Kupang yaitu kelas VII pada tanggal 17 Maret 2020. Dalam kegiatan ini, guru dan dosen bersama mahasiswa, berdasarkan RPP yang telah disusun secara bersama melaksanakan pembelajaran di kelas. Dalam pembelajaran ini, guru dan dosen serta mahasiswa melaksanakan kegiatan pembelajaran di kelas VII-a dengan menggunakan miniatur LOPO. Guru dan dosen sebagai fasilitator mengajak siswa untuk mengamati bentuk geometri datar dan geometri ruang apa saja yang terdapat pada LOPO.

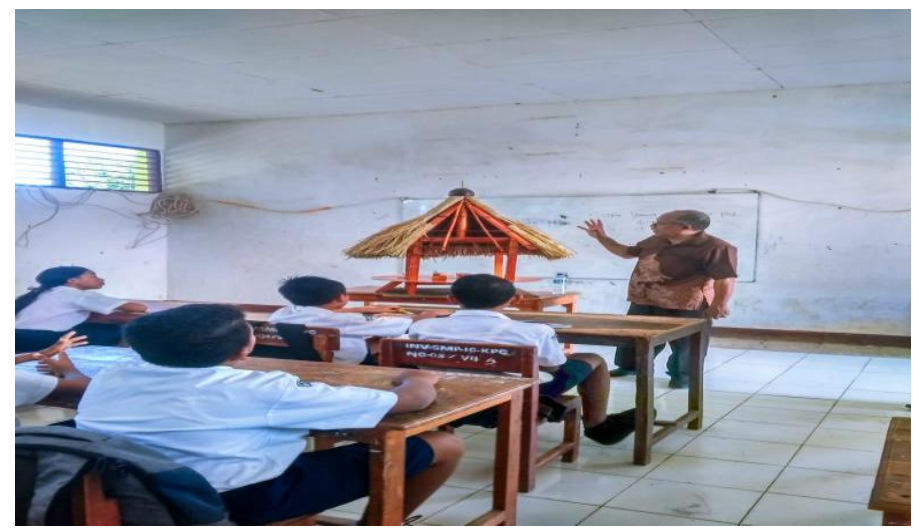

Gambar 4: Kegiatan Pembelajaran di Kelas VII-a

Dalam kegiatan awal guru bidang studi bersama dosen matematika memperkenalkan bentuk miniatur LOPO pada siswa. Pada umumnya mereka sudah melihat bentuk LOPO ini. Hanya saja LOPO yang pernah dilihat siswa digunakan untuk duduk santai atau istirahat. LOPO yang pernah dilihat siswa tidak menunjukkan adanya bentuk-bentuk geometri. Pada miniature ini justru nampak bentuk-bentuk geometri bidang dan ruang. Selanjutnya dosen dan guru mata pelajaran memberikan beberapa pertanyaan pada siswa sebagai penuntun untuk melihat bentuk geometri pada LOPO. 


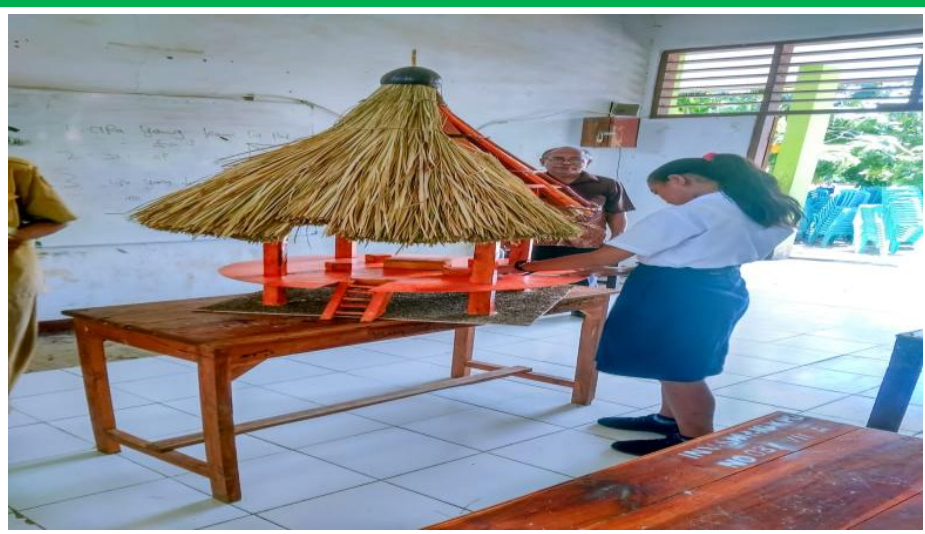

Gambar 5: Siswa untuk menentukan bentuk geometri

Pertanyaan penuntun misalnya: 1. Ada bentuk bentuk lingkaran yang terdapat pada LOPO. Jika ada, maka ada berapa banyaknya. 2. Adakah bentuk kubus yang terdapat pada LOPO. Jika ada, maka ada berapa banyaknya. 3. Adakah bentuk balok yang terdapat pada LOPO. Jika ada, maka ada berapa banyaknya. 4. Adakah bentuk Kerucut yang terdapat pada LOPO. Jika ada, maka ada berapa banyaknya. Selanjutnya siswa dituntun untuk melihat bangun datar atau bangun ruang lainnya.

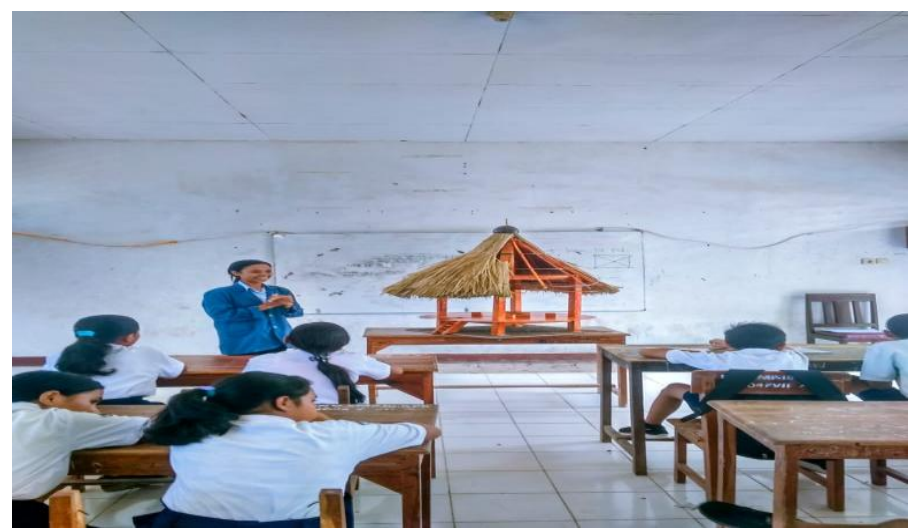

Gambar 6: Mahasiswa menjelaskan tentang bangun datar pada LOPO

Dalam hal ini diharapkan siswa telah memiliki pengetahuan dasar geometri sejak siswa berada di tingkat sekolah Dasar. Karena berdasarkan kurikulum sekolah dasar, bahwa siswa sudah diperkenalkan tentang persegi, persegi panjang Ada beberapa pertanyaan penuntun yang digunakan dalam kegiatan pembelajaran.

\section{Bagian mana dari LOPO yang berbentuk persegi.}

Dalam hal ini siswa mengamati bagian mana dari LOPO yang berbentuk persegi. Dalam pikiran siswa persegi itu bidang datar. Pembelajaran diawali dengan mengulangi konsep tentang persegi. Berdasarkan pemahaman konsep persegi itu, siswa mengamati LOPO. Siswa menemukan beberapa bentuk yang ada pada LOPO yang berbentuk persegi. Selanjutnya siswa menghitung banyaknya peregi yang ada di LOPO itu. Awalnya dari hasil pengamatan siswa, terdapat perbedaan hasil. Namun siswa mengamati ulang LOPO. Hasilnya yaitu ada kesamaan hasil pengamatan. 


\section{Bagian mana dari LOPO yang berbentuk persegi panjang.}

Dalam hal ini siswa mengamati bagian mana dari LOPO yang berbentuk persegi panjang. Pembelajaran diawali dengan mengulangi konsep tentang persegi panjang. Berdasarkan pemahaman konsep persegi panjang itu, siswa mengamati LOPO. Siswa menemukan beberapa bentuk yang ada pada LOPO yang berbentuk persegi panjang. Selanjutnya siswa menghitung banyaknya persegi panjang yang ada di LOPO itu. Awalnya dari hasil pengamatan siswa, terdapat perbedaan hasil. Ada perbedaan hasil disebabkan karena ada perbedaan pemahaman tentang persegi dan persegi panjang. Semua persegi merupakan persegi panjang. Tetapi semua persegi panjang belum tentu merupakan persegi. Sehingga perhitungan banyaknya persegi panjang berbeda. Namun siswa mengamati ulang LOPO dengan menggunakan konsep persegi panjang. Hasilnya yaitu ada kesamaan hasil pengamatan. Dalam hal ini semua persegi dihitung merupakan persegi panjang.

\section{Bagian mana dari LOPO yang berbentuk kubus}

Dalam hal ini siswa mengamati bagian mana dari LOPO yang berbentuk kubus. Dalam pikiran siswa kubus itu berbentuk ruang. Pembelajaran diawali dengan mengulangi konsep tentang kubus yang telah diperoleh di tingkat Sekolah Dasar. Ada berapa sisi kubus. Ada berapa rusuk kubus. Ada berapa titik sudut pada kubus.

Berdasarkan pemahaman konsep kubus itu, siswa mengamati LOPO. Siswa menemukan beberapa bentuk kubus yang ada pada LOPO. Selanjutnya siswa menghitung banyaknya kubus yang ada di LOPO itu. Awalnya dari hasil pengamatan siswa, terdapat perbedaan hasil. Namun siswa mengamati ulang LOPO. Hasilnya yaitu ada kesamaan hasil pengamatan.

\section{Bagian mana dari LOPO yang berbentuk balok.}

Dalam hal ini siswa mengamati bagian mana dari LOPO yang berbentuk balok. Pembelajaran diawali dengan mengulangi konsep tentang balok. Berdasarkan pemahaman konsep balok, siswa mengamati LOPO. Siswa menemukan beberapa bentuk balok yang ada pada LOPO. Selanjutnya siswa menghitung banyaknya balok yang ada di LOPO itu. Awalnya dari hasil pengamatan siswa, terdapat perbedaan hasil. Ada perbedaan hasil disebabkan karena ada perbedaan pemahaman tentang kubus dan balok. Siswa tidak memahami bahwa semua kubus merupakan balok. Tetapi semua balok belum tentu merupakan kubus. Sehingga perhitungan banyaknya balok panjang berbeda. Ada yang menemukan bahwa tidak ada bentuk balok dalam LOPO. Namun siswa mengamati ulang LOPO dengan menggunakan konsep balok. Hasilnya yaitu ada kesamaan hasil pengamatan. Dalam hal ini semua kubus dihitung merupakan balok. Dengan demikian siswa dapat menentukan ada berapa banyaknya balok dalam LOPO.

\section{Bagian mana dari LOPO yang berbentuk lingkaran}

Dalam hal ini siswa mengamati bagian mana dari LOPO yang berbentuk lingkaran. Pembelajaran diawali dengan mengulangi konsep tentang lingkaran. Berdasarkan pemahaman konsep lingkaran, siswa mengamati LOPO. Siswa menemukan beberapa bentuk lingkaran yang ada pada LOPO. Selanjutnya siswa menghitung banyaknya lingkaran yang ada di LOPO itu. Guru menjelaskan bagaimana 
mendapatkan bentuk lingkaran pada LOPO dalam kaitannya dengan bentuk kubus pada LOPO itu.

\section{Bagian mana dari LOPO yang berbentuk kerucut}

Dalam hal ini siswa mengamati bagian mana dari LOPO yang berbentuk kerucut. Pembelajaran diawali dengan mengulangi konsep tentang kerucut. Berdasarkan pemahaman konsep kerucut, siswa mengamati LOPO. Siswa menemukan beberapa bentuk kerucut yang ada pada LOPO. Selanjutnya siswa menghitung banyaknya kerucut. Siswa menemukan hubungan antara pembuatan kerucut dan lingkaran pada LOPO.

\section{Bagian mana dari LOPO yang berbentuk tabung.}

Dalam hal ini siswa mengamati bagian mana dari LOPO yang berbentuk tabung. Pembelajaran diawali dengan mengulangi konsep tentang tabung yang pernah dipelajari di tingkat Sekolah Dasar.. Berdasarkan pemahaman konsep tabung, siswa mengamati LOPO. Siswa menemukan beberapa bentuk tabung pada LOPO.

Selanjutnya siswa menghitung banyaknya tabung yang ada di LOPO. Bentuk tabung nampak pada tiang LOPO.

Dari ketujuh pertanyaan penuntun tersebut, siswa dapat mengamati konsep-konsep geometri seperti lingkaran, kubus, balok, tabung dan kerucut yang terdapat dalam LOPO etnis Timor.

\section{SIMPULAN}

Berdasarkan hasil pelaksanaan dan diskusi di atas, maka konsep-konsep geometri yang terdapat dalam LOPO etnis Timor adalah lingkaran, kubus, balok, tabung dan kerucut. Implementasi bentuk-bentuk Geometri (bidang datar dan ruang) dalam pelaksanaan pembelajaran Geometri berbasis etnis budaya Timor menjadi suatu metode yang tepat karena siswa telah mengenal LOPO sejak lahir, mereka merasa dekat dengan konteks LOPO yang digunakan dalam pembelajaran matematika. Siswa dapat mengamati dan mengkaji Geometri dalam rumah adat LOPO dengan mudah dan menyenangkan.

\section{DAFTAR PUSTAKA}

Hammond, T. 2000. "Ethnomathematics": Concept Definition and Research Perspectives," pp. 1-57, 2000.

D. C. Orey. 2018. "The Ethnomathematics Of The Sioux Tipi And Cone The people inhabiting the plains region of North America were able to," pp. 239-240, 2000.

U. D. Ambrosio.2018. "What is ethnomathematics, and how can it help children in schools? What is ethnomathematics , and how can it help children in schools?," vol. 7, no. January 2001, pp. 308-310, 2018.

D. Orey and M. Rosa. 2007. Cultural Assertions And Challenges Towards Pedagogical Action Of An Ethnomathematics Program, vol. 1. 2007

Amsikan, S. \& Deda, Y. N. 2018. Memanfaatkan Potensi Lokal Kefamenanu dalam Pembelajaran Matematika Untuk Meningkatkan Kreativitas Guru SMP. Bakti Cendana: Jurnal Pengabdian Masyarakat, 1(1), 32-40. 